\title{
Mhjournal

\section{La imagen de la Casa Real en los medios de comunicación españoles: estudio sobre la cobertura informativa en TVE y Telecinco tras la salida de Juan Carlos I al extranjero (3 de agosto de 2020)}

\author{
David Lava Santos | lasanda@alumni.uv.es \\ Universidad de Valencia \\ Isaac Pardo de Pedro | isaacpardodepedro13@gmail.com \\ Universidad Rey Juan Carlos
}

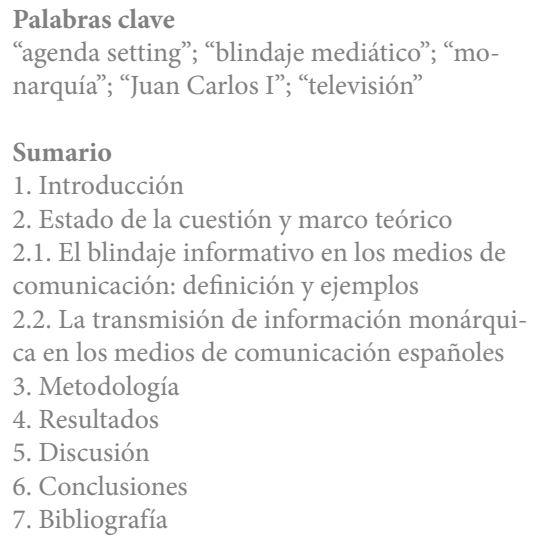

\section{Resumen}

Tras numerosos casos de corrupción y escándalos privados en los que se ha visto envuelta la casa real, el pasado 3 de agosto de 2020 el rey emérito Juan Carlos I decidió salir de España. Este suceso fue categorizado como "histórico" por parte de las televisiones, que, en su rol de agentes capaces de construir la realidad social, aumentaron la información relativa a la monarquía en sus informativos. El presente estudio analiza la cobertura informativa que dos cadenas generalistas en España, TVE y Telecinco, han ofrecido a la opinión pública sobre la coyuntura que ha rodeado la salida del ex monarca. En este sentido, se pretende conocer los temas que han estado presentes en la agenda de las cadenas, así como los protagonistas, la valoración de éstos y el estilo relativo a los informativos de cada emisora. La metodología empleada combina técnicas tanto cuantitativas como cualitativas, utilizando el análisis de contenido como herramienta de investigación. A pesar de la muestra reducida de noticias y el corto periodo analizado, se ha comprobado que el blindaje mediático, que impedía que mucha información relativa a la institución monárquica no concitara la atención pública, no ha desaparecido en las televisiones estudiadas.

\section{Cómo citar este texto:}

David Lava Santos y Isaac Pardo de Pedro (2022): La imagen de la Casa Real en los medios de comunicación españoles: estudio sobre la cobertura informativa en TVE y Telecinco tras la salida de Juan Carlos I al extranjero (3 de agosto de 2020), en Miguel Hernández Communication Journal, Vol. 13 (1), pp. 145 a 167 Universidad Miguel Hernández, UMH (Elche-Alicante). DOI: 10.21134/mhjournal.v13i.1443 
The image of the Royal Household in the Spanish media: study on news coverage on TVE y Telecinco after the departure of Juan Carlos I abroad (August, 3, 2020)

\author{
David Lava Santos | lasanda@alumni.uv.es \\ Universidad de Valencia \\ Isaac Pardo de Pedro | isaacpardodepedro13@gmail.com \\ Universidad Rey Juan Carlos
}

Keywords

"agenda setting"; "media shielding"; "monarchy";

"Juan Carlos I"; "television"

Summary

1. Introduction

2. Status of the issue and theoretical framework

2.1. Information shielding in the media: definition and examples

2.2. The transmission of monarchical information in the Spanish media

3. Methodology

4. Results

5. Discussion

6. conclusions

7. References

\section{Abstract}

After numerous cases of corruption and private scandals in which the royal house has been involved, on August 3, 2020, King Emeritus Juan Carlos I decided to leave Spain. This event was categorized as "historical" by the televisions, which, in their role as agents capable of constructing social reality, increased the information related to the monarchy in their news programs. This study analyzes the news coverage that two generalist networks in Spain, TVE and Telecinco, have offered to public opinion on the situation surrounding the departure of the former monarch. In this sense, it is intended to know the topics that have been present on the agenda of the channels, as well as the protagonists, their evaluation and the style related to the news of each station. The methodology used combines both quantitative and qualitative techniques, using content analysis as a research tool. Despite the reduced sample of news and the short period analyzed, it has been found that the media shield, which prevented much information related to the monarchical institution from attracting public attention, has not disappeared from the televisions studied.

David Lava Santos y Isaac Pardo de Pedro (2022): La imagen de la Casa Real en los medios de comunicación españoles: estudio sobre la cobertura informativa en TVE y Telecinco tras la salida de Juan Carlos I al extranjero (3 de agosto de 2020), en Miguel Hernández Communication Journal, Vol. 13 (1), pp. 145 a 167 Universidad Miguel Hernández, UMH (Elche-Alicante). DOI: 10.21134/mhjournal.v13i.1443 


\section{Introducción}

A pesar de la evidente implantación de las tecnologías digitales de la comunicación en el panorama social actual, la televisión continúa siendo el medio "preferido por la audiencia para informarse", pues casi el 50\% de la población en España sigue documentándose a través de este canal (Vicente y Monclús, 2009; Marín, 2017a: 15-17, citados en Gómez et al. 2017, 194). Ya sea en términos políticos, culturales o institucionales, la televisión establece una clara relación entre la "gente y el mundo que los rodea", y, de forma inexorable, la cobertura mediática que ofrece sobre los acontecimientos, incluyendo ciertos hechos y omitiendo otros, condiciona la experiencia que la gente tiene en su entorno más allá de sus propias vivencias (Fishman, 1983, citado en Aruguete, 2009: 12).

A este proceso mediante el cual los medios de comunicación, y en especial la televisión, influyen en las preocupaciones públicas de los ciudadanos (Casero y Rabadán, 2013: 474), es denominado teoría de la agenda setting. Esta teoría se encuentra conformada por dos niveles claramente diferenciados. El primer nivel expande su objeto de estudio hacia el conjunto específico de temas que los medios destacan (Valera, 2019), mientras que el segundo nivel se compone por los atributos relativos a cada tema en cuestión. De este modo, el primer nivel de la agenda obedece a la virtud que tienen los medios de "decir a la gente sobre qué cuestiones pensar", y en su caso, el segundo nivel, también introduce qué aspectos debe tener en consideración en relación a esas cuestiones (McCombs y Shaw, 1993; 65).

En lo que a comunicación institucional se refiere, "desde la desaparición del dictador y la entronización de la monarquía propuesta por aquel, el silencio crítico (hacia la misma monarquía) de la prensa española ha sido norma general" (De Pablos y Abreu, 2009: 67). De esta forma, la información que los medios de comunicación ofrecían a la opinión pública sobre asuntos de interés monárquico era escasa. Sin embargo, esta sensación de impunidad mediática hacia la casa real cambió de manera vertiginosa en 2010, cuando se sucedieron, años posteriores, una concatenación de escándalos de corrupción relacionados directamente con el actual rey emérito y miembros de la familia real, como el caso Noos.

Sin embargo, el objetivo de la presente investigación es analizar el tratamiento informativo de la actividad institucional monárquica que dos televisiones de referencia en España han ofrecido a la ciudadanía en un momento histórico; la salida del rey emérito Juan Carlos I al extranjero el pasado agosto de 2020. Para ello se ha llevado a cabo un análisis de contenido de una muestra de las noticias relativas a la casa real emitidas en los informativos nocturnos de TVE y Telecinco. Este diseño permite observar cuestiones tan relevantes como la imagen de la monarquía ofrecida por ambas cadenas y los temas que han estado presentes tras la salida del ex monarca. 


\section{Estado de la cuestión y marco teórico}

\subsection{El blindaje informativo en los medios de comuni- cación: definición y ejemplos}

Etimológicamente, "el uso del término escudo proviene del francés anteojera, derivado del alemán ciego. [...] El término, que se difundió con el desarrollo tecnológico y las aplicaciones en el área de seguridad" en vehículos y arquitectura civil, se ha incorporado también a cualquier fenómeno relativo a la cobertura periodística (Silveria et al. 2020: 87). Por su parte, Charaudeau (2014: 218), acompañado de Machado et al. (2020: 87) definen blindaje como una "instalación para salvaguardar a los militares", pero que, en términos periodísticos, sugiere la "acción de ocultar, enmascarar o no informar cualquier aspecto de la realidad que se considere relevante” (Silveria et al. 2020: 88). Surgiría así un término, blindaje mediático, que ha supuesto una controversia constante en la esfera pública y mediática.

Este blindaje, configurado bajo ocultaciones de información, supone un problema democrático, pues como indica Eugenia, (2016: 110) a lo largo de la historia se observa que la característica más importante del periodismo es "su actitud crítica ante los políticos" e instituciones gubernamentales. Por su parte, Donsbach (2014) resalta la tradición subjetiva del periodismo "donde lo colectivo (el espacio y el interés públicos) se encuentran en el centro de la escena" (Eugenia, 2016: 111). Uriarte (2001) también puntualiza que los medios de comunicación siempre se han caracterizado por otorgarse a sí mismos el papel de vigilantes del poder; pero sobre todo, se han caracterizado por defender los intereses de los ciudadanos transmitiendo toda la información posible sobre los asuntos de actualidad.

Sin embargo, más allá de estudiar este fenómeno bajo una lupa conceptual, conviene resaltar la aportación de Brieger (2016) cuando explica que el blindaje mediático o pacto de silencio está relacionado y se origina "por un lado, con la vinculación de los periodistas y el periodismo con el mercado, con los negocios, con la economía mundial y sus intereses subyacentes, y, por otro, con la construcción discursiva de estos medios y la consecuente polarización de la opinión pública". A pesar de sus múltiples lecturas, la contribución de Brieger (2016) infiere en que los casos de ocultación y encubrimiento de información se dan a nivel global debido a las prácticas económicas "capitalistas" y "dado el carácter empresarial de los medios de comunicación” (Donsbach, 2014 y Brieger, 2016, citados en Eugenia, 2016: 110).

A grandes rasgos, existen diversas investigaciones previas que analizan contextos periodísticos internacionales con un alto grado de blindaje informativo. En el caso del estudio aportado por Paulón (2018: 7), los autores destacaron que, tras la emisión del primer Decreto de Necesidad y Urgencia por parte del presidente argentino Mauricio Macri en 2015, "se desencadenó el peor avasallamiento mediático [...] presenciando el crecimiento del blindaje mediático que protege al gobierno actual e invisibiliza las protestas sociales, las represiones y las decisiones estatales que afectan a la población". De igual manera, en el estudio de Aguilar et al. (2013: 68), demuestra que en Chiapas (México) "el despojo de las tierras de los campesinos y su uso como fuerza de trabajo liberada al servicio de los intereses de la acumulación del capital [...] se legitimó bajo el blindaje mediático", pues, o se omitía infor- 
mación, o la que se aportaba era engañosa.

Sin embargo, los blindajes o cordones informativos no sólo afectan a la comunicación relativa a gobiernos y partidos políticos, sino que organizaciones no gubernamentales e instituciones alejadas de la política también hacen uso de esta práctica perjudicial para la democracia. En el trabajo de Hoyos (1999) se demuestra que muchas ONGs, amparadas bajo los medios de comunicación, no denuncian la "lluvia ácida, la desertización, el cambio climático, la destrucción de bosques y selvas y el progresivo exterminio de la biodiversidad".

Queda establecido, por ende, que diversas instituciones internacionales, favorecidas por los medios de comunicación, no muestran a la ciudadanía las prácticas que llevan a cabo internamente. En el caso de la presente investigación, queremos centrarnos en el caso de la monarquía española, pues desde el inicio de la democracia, los medios de comunicación españoles se han caracterizado por ejecutar una estrategia prácticamente unívoca en el proceso de transmisión de información monárquica a la ciudadanía (Carratalá, 2014: 130). Además de "cordón sanitario" o "blindaje mediático" (López y Valera, 2013: 67), Ramos, (2013: 27) también denomina "pacto de silencio" a la "comunión de intereses entre los medios y determinadas facciones del poder político", que ha permitido, en este caso a la casa real, "delimitar su presencia mediática tanto en términos cuantitativos como cualitativos" (López y Valera, 2013: 67).

\subsection{La transmisión de información monárquica en los me- dios de comunicación españoles}

Desde su implantación en 1975, la monarquía en España ha sido capaz de soslayar una gran cohorte de rumores e informaciones que circulaban por los medios de comunicación y que no han llegado a concitar la atención mediática. Autores como Barredo (2013: 3) y Ramos (2012: 4) destacan que la monarquía española es uno de los entornos informativos y sociales más restrictivos para los periodistas y medios en la democracia actual, y señalan diversas causas que convierten, precisamente a la casa real, en un tema vetado por los medios de comunicación:

Para empezar porque el Rey Juan Carlos, a diferencia de otras figuras públicas, no suele responder a ningún tipo de pregunta. [...]. Pero es que además los periodistas se enfrentan [...] a un blindaje a través de los artículos 490 y 491 del Código Penal español, [...], y a un aparato legal que incluso el Tribunal Europeo de Derechos Humanos ha criticado por la sobreprotección del sistema monárquico (Barredo, 2013: 3).

En su caso, Cano y Llorca (2017: 31) no sólo ofrecen algunas de las claves que han llevado a la monarquía a mostrar una imagen prácticamente inmaculada en los diversos medios de comunicación, sino que en su investigación recalcan que, en la representación que estos medios ofrecen a la opinión pública se evidencia una clara "identificación de la imagen del Rey con los valores de la democracia", equiparando al jefe de Estado con una efigie de unidad y de "convivencia entre los españoles". Así, esta concatenación de causas que justifican la "tolerancia, ignorancia o tratamiento benévolo" (Ramos, 2012: 6) por parte de los medios de comunicación hacia la figura del rey y a la monarquía en general, es lo que 
Ramos (2012: 6) denomina como "amnesia periodística” y como se indicaba al inicio de este epígrafe, supone que durante los años del reinado de Juan Carlos I, los medios, salvo contadas ocasiones, se hayan "autoadministrado pequeñas dosis de amnesia" sobre la información referida a la monarquía.

Resulta evidente la particular dificultad que tienen los periodistas a la hora de mostrar información sobre el rey o la casa real a la ciudadanía. No obstante, esta situación de inviolabilidad mediática cambió de manera vertiginosa gracias a una serie de transformaciones sociales.

Primero, por efecto de las nuevas tecnologías y la multiplicación de medios [...]. Y, en segundo lugar, por un factor generacional: el público más joven, nacido y educado en democracia [...], que no ha vivido la época de la Transición, indudablemente otorga menos valor que las generaciones precedentes a la figura de Juan Carlos I y a la propia institución monárquica (López y Valera, 2013: 68).

Además, a estos cambios estructurales se sumó el desencadenamiento de una serie de escándalos que afectaron a distintos miembros de la casa real (Lluch, 2014: 9), tales como la imputación de Urdangarin por el Juez Castro, el 29 de diciembre de 2011; el accidente sufrido por Juan Carlos I mientras cazaba elefantes en Botsuana, a raíz del cual tuvo que pedir perdón públicamente y, finalmente, "el salto a la opinión pública de su acompañante zu Syan- Wittgestein” (Velasco, 2018: 126).

Estos casos implicaron un cambio estructural en el tratamiento informativo respecto a la casa real, y los medios de comunicación, en particular los digitales, dejaron en gran medida de ser partícipes del "cordón sanitario" a la monarquía (López y Valera, 2013: 69). Sin embargo, si existe un momento de máxima expectación mediática en torno a la casa real y al rey, fue la salida del monarca de España el pasado 3 de agosto de 2020. Este suceso propició que todos los medios dedicaran sus espacios informativos a emitir la información relacionada con la casa real. Además de redes sociales, prensa y radio, la televisión, fue una de las plataformas que evidenció su presencia pública y dedicó una amplia cantidad de minutos en sus parrillas a hablar sobre el escándalo de la casa real.

Como se ha comprobado, hasta el momento son pocas las investigaciones que hacen referencia al tratamiento que los medios de comunicación realizan sobre la casa real española, exceptuando las ya citadas de Ramos (2012), López y Valera (2013) o Cano y Llorca (2017). Además, resulta oportuno analizar la cobertura informativa que las televisiones han ofrecido a la ciudadanía sobre la casa real debido al evidente interés mediático que la salida del monarca y su posterior localización concitó entre la sociedad española.

Por ello, esta investigación se propone analizar la imagen que los informativos nocturnos de dos de las cadenas generalistas de referencia en España, TVE y Telecinco han ofrecido a la ciudadanía sobre la casa real desde la salida del monarca de España hasta su posterior localización en los Emiratos Árabes el 16 de agosto de 2020. El motivo de este propósito 
se debe a que la decisión del rey de salir de España el pasado 3 de agosto, contribuyó a que la carga informativa que los medios de referencia expusieron a la opinión pública se viera incrementada notablemente.

Se pretende evidenciar así la hipótesis general de que los medios de comunicación tradicionales, y con ellos la televisión, han ofrecido una cobertura crítica respecto al último suceso acontecido en la casa real, matizado siempre por la línea editorial de cada cadena (López y Valera, 2013: 69).

Desde la perspectiva de la agenda setting y el creciente interés mediático sobre la monarquía, la presente investigación pretende dar respuesta a los siguientes objetivos:

- O1: Identificar los temas relacionados con la monarquía que han supuesto una mayor relevancia en la agenda temática de las televisiones analizadas, durante la salida del rey de España y su posterior localización en los Emiratos Árabes.

- O2: Especificar qué miembros de la casa real aparecen con mayor frecuencia en los informativos analizados, así como la valoración que se ofrece sobre los mismos. De igual manera, comprobar si en las noticias relativas a la casa real aparecen otras figuras cercanas a instituciones públicas y políticas.

- O3: Identificar el estilo de presentación de las noticias que los informativos han ofrecido a la audiencia durante el periodo analizado.

De acuerdo con estos objetivos, las hipótesis que se pretenden alcanzar son las siguientes:

- H1: Los temas relacionados con la casa real que las televisiones marcarán en su agenda se corresponden, principalmente, con las cuestiones judiciales relacionadas con el mismo ex monarca, obteniendo así, en lo relativo a estas cuestiones, un carácter evidentemente perjudicial para la institución.

- H2: Dada la salida inesperada del rey emérito, el miembro que aparecerá con mayor frecuencia en los informativos analizados será Juan Carlos I, y la valoración que se emitirá a la audiencia sobre él será claramente desfavorable. Sin embargo, también se espera que aparezca en los informativos la familia real en general, y que la valoración sobre los mismos sea también de carácter negativo o presentando una mayor neutralidad. Asimismo, se espera que las televisiones también introduzcan en sus informativos a los diversos personajes y miembros del gobierno y los partidos políticos.

- H3: El estilo de las noticias en las cadenas analizadas será interpretativo, pues se espera que los periodistas analicen y evalúen la situación relativa a la casa real. En el caso de la cadena privada, Telecinco, presentarán un estilo más subjetivo acorde a su línea editorial, mientras que TVE en su condición de cadena pública, pretenderá mostrar una imagen más neutra de la institución monárquica. 


\section{Metodología}

Para llevar a cabo la investigación, hemos optado por combinar una metodología tanto cuantitativa como cualitativa, siendo el método fundamental de estudio el análisis de contenido. Cabe destacar que el análisis de contenido cuenta con un mayor peso cuantitativo que cualitativo (Gómez et al 2017: 198) por lo que los resultados supondrán una aportación tanto demostrativa, gracias a la parte cuantitativa, como descriptiva, gracias a la parte cualitativa, de la información analizada. El análisis de contenido consigue reconstruir la arquitectura, conocer la estructura, los componentes básicos y el funcionamiento de los propios mensajes mediáticos (Igartua y Humanes, 2004:8).

Debido a la evidente situación de inestabilidad institucional que la casa real lleva viviendo durante los últimos 9 años y que culminó con la salida del monarca de España el pasado 3 de agosto de 2020, se ha decidido analizar la cobertura televisiva tomando como fecha de referencia las semanas inmediatamente posteriores a la salida de Juan Carlos I, comprendidas entre el 3 de agostos de 2020 y el 23 de agosto de ese mismo año. Se pretende evidenciar así que, con la introducción de temas negativos y protagonistas cuya valoración por parte de los periodistas sea desfavorable, los informativos de las televisiones analizadas han empleado un tono y estilo que presenta una mayor subjetividad y crítica.

Para la selección del corpus de noticias y la realización del contraste de los objetivos, las cadenas escogidas fueron TVE y Telecinco. Esta selección se debe principalmente a que se ha buscado la representación tanto de cadenas públicas como privadas. También a su condición de cadenas que logran unos niveles de audiencia elevados, pero, sobre todo, a su condición de televisiones cuya línea editorial es distinta, y por tanto; la televisión pública busca producir información a partir de criterios de equilibrio y neutralidad y Telecinco, presenta un modelo comercial basado en la búsqueda masiva de audiencias (Humanes et al. 2013: 579). Asimismo, se ha optado por analizar los informativos nocturnos porque acumulan más audiencia, "contienen videos ya emitidos al mediodía y añaden algo más para actualizarlos” (Ramos- Ruiz, 2015: 9).

En el caso de TVE, se trata de un informativo "con un perfil convencional, donde prima la información sobre el espectáculo” (Gómez et al. 2017:209). Además de ser la emisora pública de referencia en España y de alcance estatal, TVE cuenta con unos informativos que responden a la función de servicio público, pretendiendo "dar respuesta a una estructura tradicional donde priman las informaciones [...] extensas y elaboradas". Además, en términos de audiencia, la televisión pública superaba el millón de espectadores los días 3 de agosto, cuando se conocía la noticia relacionada con la salida de Juan Carlos I de España, y el 16 de ese mismo mes, cuando se descubría el paradero del ex monarca.

Por su parte, Telecinco es una de las dos grandes cadenas privadas, y como sostienen Gómez et al (2017: 209), sus informativos cuentan con un tono más apelativo, sensacionalista y emocional que la cadena pública. Asimismo, sus informativos nocturnos obtenían el 16,7\% de share el día 3 de agosto, y el 13,9\% el día 16, momentos considerados de máxima 
expectación en términos de información monárquica. Además, durante el periodo analizado, ninguno de sus informativos el número de espectadores bajó del millón.

La muestra inicial de noticias dedicadas a hablar sobre la casa real en los informativos es relativamente amplia teniendo en cuenta que la información habitual ofrecida por las televisiones sobre la institución suele ser escasa, y a que el escándalo del monarca se ha dado en medio de una situación de pandemia mundial, lo que ha generado que las televisiones dediquen casi de manera exclusiva el informativo a hablar sobre esta crisis sanitaria. Así, este estudio cuenta con un total de 81 unidades de análisis; 49 noticias emitidas por TVE y 35 por Telecinco.

La actividad de noticias seleccionadas se escogió de las versiones web de los informativos completos nocturnos de TVE y Telecinco, y, para facilitar la búsqueda de las unidades de análisis, realizamos una lista con los informativos ordenados cronológicamente. La recopilación de las noticias y la operacionalización de los datos se llevó a cabo mediante la herramienta estadística y hoja de cálculo de Excel.

Paralelamente, para la obtención de los datos se elaboró una ficha de análisis con 12 variables agrupadas en 5 bloques bajo un procedimiento deductivo, pues "hemos partido de una intuición sobre cuál puede ser la explicación de los comportamientos particulares" de nuestro objeto de estudio y, a partir de la observación, se han aislado conceptualmente esos elementos que creemos que vamos a configurar (i Cespedes y i Artés ,2020: 24)

"Bloque de codificación": compuesta por las variables cadena que se analiza y fecha de la noticia. Ambas se han elaborado para establecer cruces de variables y poder comprobar si existen cambios significativos en el tratamiento que las cadenas han ofrecido sobre la casa real.

"Enfoque temático de la noticia": Se han distinguido tres variables diferentes; temas, protagonista de la noticia y personaje con el que se le relaciona al protagonista. La variable relativa a los temas ha sido categorizada mediante el contexto de la situación monárquica, lo que supone evidenciar que la salida del rey emérito haya sido de manera inexorable el tema principal en torno al que sucedían las noticias, por lo que los asuntos escogidos han sido elaborados ad hoc para nuestra investigación e incluyen los temas relacionados con la actividad monárquica más reciente (cuestiones judiciales de la casa real, cuestiones concernientes a la vida privada del Rey, cuestiones relativas a la historia y valores de la casa real, aptitudes políticas, etc.), mientras que los temas de debate clásico en torno a esta situación (disyuntiva entre Monarquía o República, apoyos sociales, etc.) se han escogido por la metodología aportada por López y Valera (2013: 71). Por ende, las categorías se han diseñado adecuándose al contenido de las noticias para formalizar el análisis (Cano y Llorca, 2017: 41), y se ha considerado la salida de Juan Carlos I como el tema principal de cada noticia, precisando así que la categorización de los temas gira en torno a esta cuestión principal. Las variables protagonista de la noticia y personaje con el que se le relaciona al protagonista son de carácter 
abierto con la idea de que la posterior recodificación de los valores encontrados permita un conocimiento más cercano sobre los objetivos planteados (Rabadán y Mariño, 2011: 5).

"Relevancia de la noticia": A partir de la literatura previa (Igartua et al. 2005: 5 y Humanes, 2001: 5) se evalúan el emplazamiento de la noticia, su duración, la posición en el informativo y los recursos utilizados. Así, se recoge si la noticia aparece o no en el sumario, la posición que ocupa dentro del informativo (en primer lugar o en otro lugar), los recursos que se han utilizado (imagen y sonido, si la noticia incluye imágenes de la información y las declaraciones de los protagonistas tanto en directo como en diferido; sólo imagen, si aparecen imágenes sin las declaraciones de los protagonistas, y finalmente, gráficos o esquemas si incluyen información adicional), y finalmente, el análisis permite comprobar el tiempo dedicado a hablar sobre la información referida a la casa real en un cómputo de tiempo establecido entre los 30 segundos y más de 4 minutos de duración.

"Estilo de la noticia": Se hizo una distinción entre estilo descriptivo, estilo interpretativo y estilo crítico gracias a la metodología aportada por Humanes et al. (2013: 570). Estos indicadores están relacionados con el estilo periodístico, y hacen referencia al posicionamiento del periodista respecto a la acción o al actor de la noticia. De esta forma, en las noticias con estilo descriptivo el periodista cuenta exclusivamente la información relativa a la monarquía; en las noticias de carácter interpretativo, el periodista analiza y evalúa la situación monárquica mientras se describe, y mediante el estilo crítico, si aparece deliberadamente la opinión de los periodistas.

"Atributos de los personajes": Se evalúa la valoración que la cadena hace sobre los distintos protagonistas y personajes con los que se le relaciona al protagonista mediante tres categorías; positiva, negativa y neutra sin atender a gradaciones. La valoración es positiva cuando el suceso o sus posibles consecuencias son juzgadas como deseables para la monarquía o sus miembros. En el caso de que el suceso y sus consecuencias sean juzgadas como no deseables, la valoración era negativa, $y$, finalmente, la noticia es neutra cuando la noticia contaba exclusivamente lo que sucedía. En relación con el bloque anterior (estilo de la noticia), cabe destacar que las noticias con estilo interpretativo y crítico se codificaron según la valoración que hace la emisora respecto a los actores de la noticia: positiva, negativa o neutra. En el caso del estilo descriptivo, la valoración de la cadena respecto al actor será tomada exclusivamente como neutra.

\section{Resultados}

Para demostrar la fiabilidad de la investigación, la obtención de los resultados fue realizada por los dos investigadores que componemos el presente estudio. Así, ambos analizamos de manera independiente la totalidad de la muestra, examinando la variable creada ad hoc para el trabajo; temática de la noticia, y las variables que podían contar con una mayor discre- 
pancia en los resultados por su grado de subjetividad; estilo de la noticia, valoración sobre el protagonista y valoración sobre el personaje al que se le relaciona al protagonista. Para establecer el grado de concordancia en los resultados obtenidos, se codificó el 15\% de las unidades de análisis mediante la herramienta ReCal OIR (Reliability Calculator for Ordinal, Interval and Ratio data), desarrollada por el profesor de la UNC-Chapel Hill, Deen Freelon.

De esta forma, el cálculo, en relación con el coeficiente de Alpha de Krippendorff, ofreció unos valores altos de concordancia respecto al tema (Krippendorff's Alpha 0,932), los atributos del protagonista (Krippendorff's Alpha 0,907), el estilo de presentación de las noticias (Krippendorff's Alpha 0,817), y un valor para los atributos relacionados con el personaje al que se le relaciona al protagonista (Krippendorff's Alpha 0,733) que se ha considerado aceptable para la solidez de la investigación.

El análisis de contenido ha permitido revelar que la distribución de las noticias analizadas en cada cadena es aparentemente desigual. De esta forma, si bien cuantitativamente es mayor la muestra de TVE, se ha de tener en cuenta que tal diferencia también obedece a la proporción temporal de los informativos, pues si la duración de un noticiario completo en TVE oscila por lo general, entre los 50 y 55 minutos, los informativos de Telecinco no superan los 32 y 38 minutos de duración. Se observa así que, a pesar de existir una diferencia de 17 noticias entre ambas emisoras, los asuntos relacionados con la casa real han ocupado un espacio informativo similar en las parrillas de sus informativos.

Figura 1: Cantidad de noticias por cadena

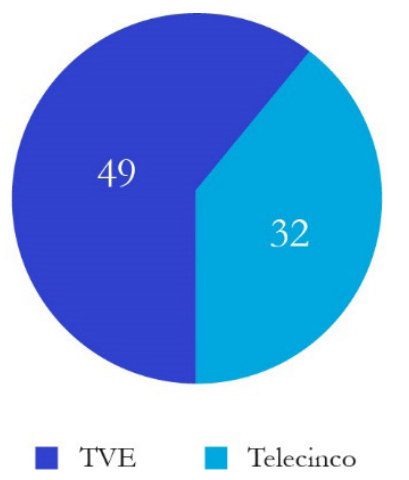

Fuente: elaboración propia

Por otra parte, según el momento analizado y a medida que avanzaban los días dentro del periodo investigado, se produjo una clara disminución en el interés de este suceso "histórico". Esto se traduce en una reducción de las noticias en los informativos de los días siguientes a que Juan Carlos I decidiese salir de España. Así, se aprecia que tanto TVE como Telecinco emitieron el mismo día de la salida del monarca una cantidad de noticias relacionadas con la casa real que superaron con creces otros temas como la pandemia provocada por el coronavirus, o temas de carácter plenamente político y cultural. 
Parece lógico, entonces, asumir que la distribución de las noticias y el interés por la salida del rey Juan Carlos en los informativos analizados se redujera a medida que pasaban los días comprendidos dentro del periodo analizado. De hecho, aunque entre los días 3 y 4 de agosto los informativos de ambas televisiones dedicaran la mayoría de minutos a ofrecer el prisma contextual que rodeaba la salida del ex monarca, tras más de una semana en la que, como se estableció en la parte metodológica, el hilo discursivo giraba en torno a la salida del rey emérito de España, el día en el que se descubrió el paradero de Juan Carlos I y en adelante, las noticias no se vieron incrementadas. Merece la pena destacar que, en los informativos de TVE, no se llegó a mencionar el día 16 de agosto, domingo, que Juan Carlos I se encontrara en los Emiratos Árabes; información que Telecinco sí ofreció.

Figura 2: Temática de las noticias según cadena

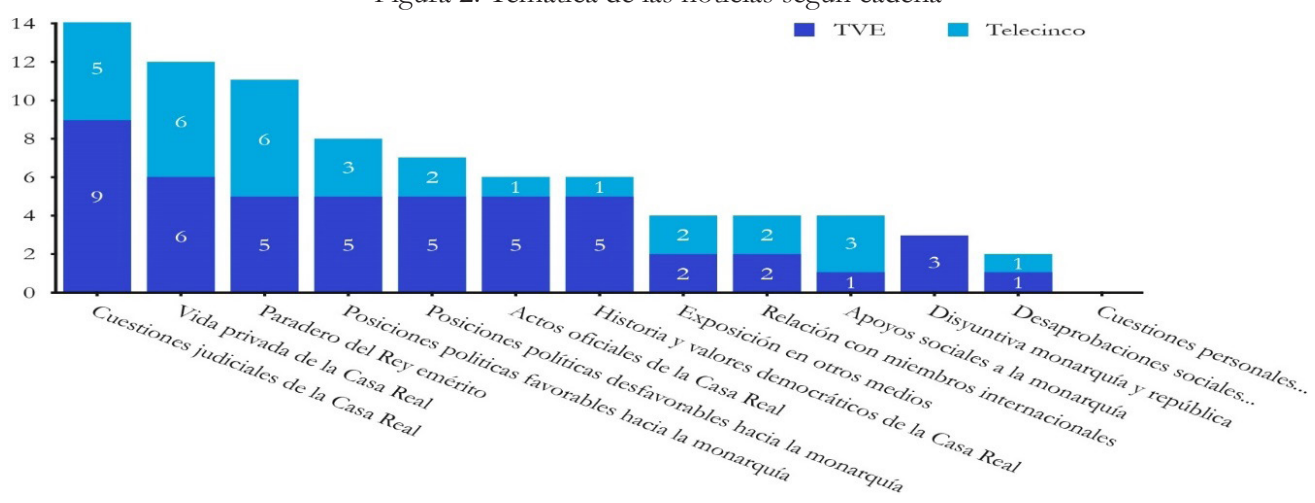

Fuente: elaboración propia

En lo referente a la temática principal de cada noticia, en términos generales, los asuntos relacionados con las cuestiones judiciales de la casa real ocupan 14 noticias, lo que supone el $17,3 \%$ del total. El blanqueo de capitales, las transferencias irregulares y el cobro de comisiones por el AVE a la Meca, han sido las informaciones que de manera habitual han ocupado el espacio informativo y que, por tanto, han ejercido un protagonismo significativo en las agendas de las televisiones.

Coincidiendo con el periodo estival, la vida privada de la casa real ha concitado parte de la atención mediática con un total de 12 noticias entre ambas emisoras. Dado que las vacaciones de la familia real en Mallorca es un tema que ha aparecido de forma habitual en las agendas mediáticas; este año, como cabía esperar, su tratamiento ha sido diferente. Desde una perspectiva más cualitativa, se ha comprobado como en el discurso que ambas cadenas ofrecen sobre las vacaciones de la familia real, pretenden mostrar que a pesar de estar de vacaciones, la casa real tiene una agenda apretada y llena de actos oficiales. Asimismo, cabe destacar que durante el asueto real, los periodistas preguntaron de forma directa a los reyes por el paradero del rey emérito, sin obtener ningún tipo de respuesta por parte de la casa real, pues, según está, era competencia del rey emérito y no de Zarzuela indicar su ubicación. 
Segregando los datos, la temática más relevante en la televisión pública fueron las cuestiones judiciales de la institución real, con nueve noticias. La vida privada de la casa real ocupó el segundo lugar con un $12,2 \%$ de noticias y, tras ella, con cinco noticias y un $10,2 \%$ del total se encuentran las posiciones políticas favorables hacia la monarquía. En lo relativo a Telecinco, las temáticas más representadas fueron el paradero del Rey emérito y la Vida privada de la casa real, con seis noticias y un total del 18,75\% respectivamente. Las Cuestiones judiciales de la casa real $(15,6 \%)$ también consiguieron una ímproba atención en los informativos de la televisión privada.

Si bien cuestiones como las posiciones políticas desfavorables hacia la monarquía, los apoyos sociales, el paradero del Rey emérito, la Historia y valores democráticos de la casa real, o la disyuntiva entre Monarquía o República no han supuesto un porcentaje significativo en el conjunto de la agenda temática de los informativos, esto no es óbice para que en diversas ocasiones, hayan aparecido en el sumario y cuenten con una cantidad de minutos lo suficientemente amplia como para ofrecer un valor significativo en el cómputo global del noticiario. De hecho, los asuntos relacionados con la historia y valores democráticos aparecieron en sumario el 2,1\% de las ocasiones en TVE, y las cuestiones relacionadas con los apoyos sociales a la monarquía el 2,9\% en Telecinco, por ejemplo.

Como claro ejemplo, la televisión privada realizó una entrevista exclusiva al vicepresidente Pablo Iglesias en la que el propio entrevistado ofrecía una visión peyorativa de la monarquía explicando que "era hora de establecer en el debate público la disyuntiva entre Monarquía o República". Por el contrario, en el caso de los informativos de TVE, se ofreció el trozo de un documental en el que aparecía hablando Juan Carlos I en un tono emocional recordando las víctimas de ETA, o acentuando su papel fundamental en los valores democráticos tras el 23-F.

El análisis de las variables abiertas ha permitido detallar que el rey emérito es el personaje que copa el protagonismo de la información recabada, apareciendo en 28 noticias, es decir, en más del 34\% de las ocasiones. El siguiente personaje que mayor presencia ha mantenido en el cómputo global de las noticias es el rey Felipe VI, en 10 noticias, lo que supone el 12,3\% del total, seguido de la Familia Real y la casa real, con nueve y siete noticias respectivamente. Corinna zu Sayn-Wittgenstein, la Reina Sofía y el presidente del Gobierno, Pedro Sánchez, son algunos de los protagonistas que han tenido relación con los asuntos referidos a la casa real.

El sujeto protagonista, en ocasiones, se presenta en relación directa con otros personajes, entre los cuales se aprecia, al igual que en la anterior categoría, que es también el rey emérito la figura predominante en esta categoría. Juan Carlos I aparece hasta en 30 ocasiones -el $37 \%$ de las noticias-, con una amplia diferencia respecto al resto: la casa real, con ocho apariciones; el rey Felipe VI, con siete; Corinna zu Sayn-Wittgenstein y el Gobierno, que aparecen en tres ocasiones; determinados expertos y periodistas hasta en dos ocasiones cada uno.

Por lo tanto, cabe destacar que la figura del rey emérito Juan Carlos I, bien como protago- 
nista o como personaje directamente relacionado, aparece en un total de 58 noticias, lo cual corresponde al $71,6 \%$ de la muestra y se entiende dentro del contexto de su salida del país.

Figura 3: Protagonista de las noticias según cadena

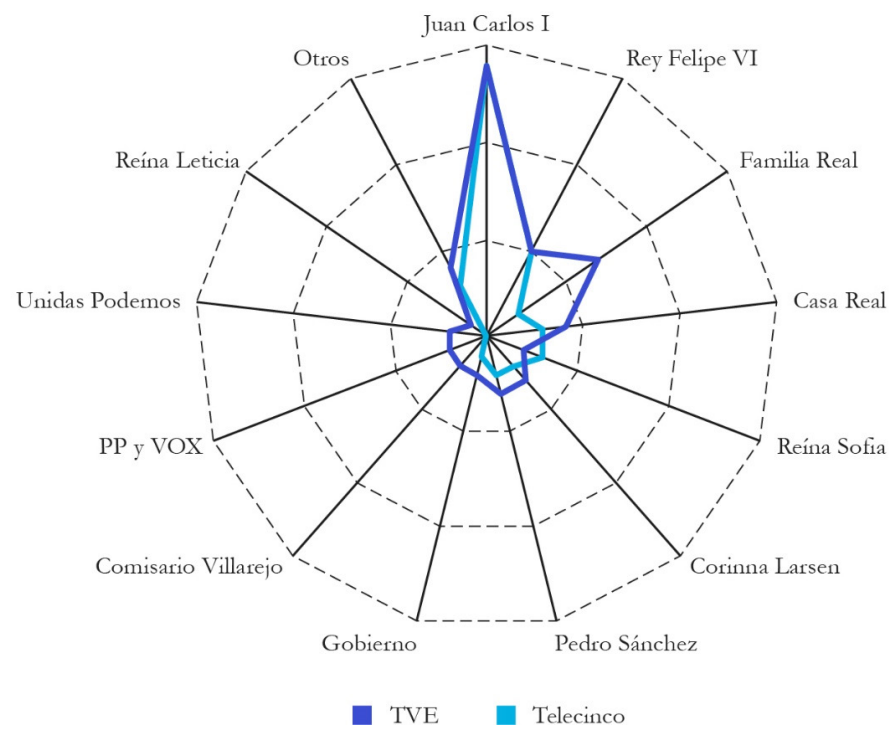

Fuente: elaboración propia

La siguiente figura más representada es el actual rey Felipe VI, quien aparece hasta en 17 ocasiones en estas dos categorías, es decir, en un $21 \%$ del total.

Al realizar la distinción por cadenas se observan ciertas disimilitudes a pesar de que, como puede presuponerse, el cómputo global no varía en exceso. De este modo, tanto TVE como Telecinco coinciden en el protagonista de las noticias, Juan Carlos I, dedicándole ambas la atención principal en 14 de sus noticias, lo cual supone el 28,6\% del total de noticias de TVE y el $43,75 \%$ de las noticias de Telecinco, que reúne en mayor proporción sus informaciones en la figura del rey emérito. Esto se constata aún en mayor medida al observar la categoría de personajes relacionados, también encabezada por Juan Carlos I en ambas cadenas en un total de 18 noticias por parte de TVE -36,7\%- y 14 por parte de Telecinco -37,5\%-. Por lo tanto, el rey emérito aparece en el 65,6\% de las noticias de TVE como personaje principal o directamente relacionado y hasta en el $81,25 \%$ de las noticias de Telecinco.

Resulta realmente esclarecedor, a la hora de comprender la imagen que se ha ofrecido sobre la casa real, comprobar la valoración que ambas televisiones han emitido a la ciudadanía sobre los protagonistas de las noticias. Así, la figura del rey emérito ha obtenido una evidente centralidad en los informativos analizados y su valoración ha sido mayoritariamente negativa. La evidencia empírica de los datos recabados demuestra que en 15 noticias en las que el ex monarca era el protagonista, las televisiones hablaban de su figura dentro de un 
entorno de corrupción y escándalos familiares.

En efecto, cuando el rey era situado en un contexto de relación con otros personajes, se le solía mostrar al lado de "su amiga íntima" Corina, o con jeques árabes que, como ha indicado TVE; “tenían relación con la muerte del periodista Yamal Jashogyui”. No obstante, cabe destacar que TVE ha ofrecido un mayor número de noticias cuya valoración sobre el ex monarca estaba dentro de la neutralidad, intentando así no mostrar una opinión ni a favor ni en contra del rey emérito.

Como se ha comentado anteriormente, se confirma que Felipe VI ha aparecido en gran medida dentro de los informativos con una evaluación sistemáticamente neutra o erigiéndose como el monarca que aboga por "una mayor transparencia en la institución, llegando a ofrecer al patrimonio social los regalos que la casa real reciba de fuentes exteriores", y "protector de la institución". Asimismo, los diversos miembros de la familia real, entre los que se encuentran la Reina emérita o la Princesa Leonor, también obtienen en los informativos una valoración que varía entre lo positivo y lo neutro.

En efecto, que la figura de Juan Carlos I haya sido tratada mayoritariamente de forma negativa por las cadenas analizadas, acredita holgadamente que es el ex Monarca el único culpable de la perturbación de la vida de la institución real. Con las apariciones de partidos como PP, Vox, e incluso con las declaraciones de Pedro Sánchez, se ha repetido que "se debe desligar la figura de Juan Carlos a la Monarquía como Institución”. Sin embargo, resulta curioso afirmar que, ambas televisiones también han ofrecido, en pocas ocasiones teniendo en cuenta el cómputo de información, una imagen que liga a la figura del rey emérito con los valores de democracia y el prestigio histórico-social.

Figura 4: Estilo de las noticias según cadena

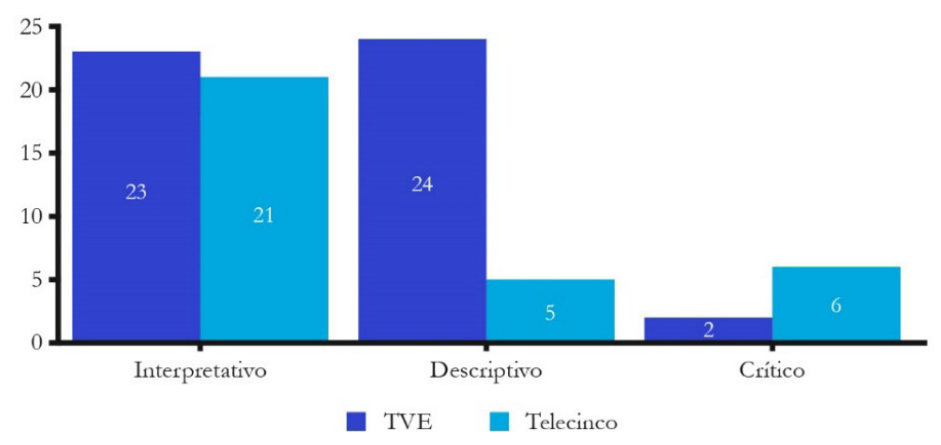

Fuente: elaboración propia

Finalmente, como muestra la figura 4, desde el punto de vista del estilo de presentación de las noticias, por nuestro interés específico de conocer las diferencias entre las cadenas analizadas, no resultaba significativo averiguar el balance global, sino las varianzas porcentuales. Así, aunque ambas cadenas comparten resultados similares en cuanto a noticias de estilo interpretativo; 23 en TVE y 21 en Telecinco, es la televisión 
pública quien presenta una cantidad mucho mayor de noticias de carácter descriptivo; 24, y que, por tanto, se ofrece exclusivamente lo que ocurre, sin ningún tipo de interpretación, mostrando una mayor objetividad en la presentación de las noticias que tienen que ver con la casa real. Por el contrario, Telecinco sólo ofrece cinco noticias con estilo descriptivo, triplicando así las noticias de estilo crítico respecto a TVE; 6 noticias de estilo crítico para la televisión privada y 2 en la pública.

\section{Discusiones}

Las limitaciones de nuestro estudio coinciden con las aportadas por otros autores, como Cano y Llorca (2017: 47), sobre el escaso recorrido temporal que conforman el corpus de nuestra investigación, lo que "limita la posibilidad de apreciar la estrategia comunicativa" que han utilizado las televisiones en su ímpetu por establecer una imagen sobre la casa real. Además, que el presente análisis se haya realizado exclusivamente estudiando dos cadenas, dificulta, precisamente, que los resultados sean extrapolables al conjunto de las cadenas de televisión, por lo que puede considerarse como la principal limitación estructural de la investigación (Salaverría et al. 2020: 13). Finalmente, la escasa cantidad de literatura previa también pueden considerarse como limitación sustancial de la investigación.

En cualquier caso, la investigación ha corroborado que el hermetismo en términos de información monárquica sigue vigente en la actualidad. Así, como evidenciaron empíricamente López y Valera (2013: 79) en su investigación, la ruptura del "cordón sanitario" que protegía a la casa real sólo se produjo en los medios de comunicación digitales; mientras que los resultados aportados por esta investigación demuestran que, en las televisiones analizadas, el blindaje mediático en torno a la monarquía sigue patente. Investigaciones futuras podrán ampliar los resultados aquí recabados mediante el estudio del tratamiento en las noticias de ambas cadenas anteriores a la salida de Juan Carlos I.

La salida del monarca el día 3 de agosto de 2020 fue categorizada por ambas cadenas como "una noticia de carácter histórico". Los informativos de la televisión pública dedicaron ese mismo día la mayor parte del noticiario a ofrecer noticias relacionadas con la casa real y el rey emérito. De manera similar, Telecinco ocupó la mayoría de su parrilla de programación a temas relacionados con la institución monárquica.

En el ámbito empírico, nuestro estudio confirma que, en contra de los esperado, las noticias que las televisiones han ofrecido a la ciudadanía (H1) sobre la casa real ofrecen una clara diversidad temática. Ambas cadenas han optado por construir una agenda en torno a la monarquía con la mayoría de los temas recogidos en nuestra hoja de codificación. De esta forma, las cuestiones judiciales de la casa real cuentan en ambas emisoras con un holgado porcentaje, pero éste no es significativo en comparación con otros temas como la vida privada del rey emérito, la vida privada de la familia real o los temas de historia y valores democráticos de la casa real.

No obstante, existen diferencias notables entre las cadenas analizadas, pues los resultados sugieren que las cuestiones judiciales de la casa real y las posiciones políticas favorables 
hacia la monarquía suponen una tendencia primordial en torno al contexto de la salida del rey en la televisión pública. Mientras que, en el caso de Telecinco, su discurso no se construye en torno a un tema que ocupa la centralidad de sus informativos, sino que se pretende ofrecer mayor diversidad de temas relacionados con la monarquía. De esta forma el análisis de contenido ha revelado que la salida del rey emérito proliferó el aumento de noticias relacionadas con la casa real, abordando todas las dimensiones posibles según el contexto de evidente crisis institucional, lo que refuta por completo la primera hipótesis.

Los ejes temáticos responden a un prisma de información evidentemente sobrerrepresentado que pretende ahondar en toda la información relativa a la casa real. Pero sobre todo, las televisiones, registran una clara matización que distingue, precisamente a la casa real, con la figura del rey emérito. Por razones evidentes, el análisis ha manifestado que es Juan Carlos I el principal protagonista de las noticias analizadas (H2). De igual manera, cuando el protagonista de la noticia es otro miembro de la casa real o de la actualidad mediática, es el rey emérito el personaje con el que más se le relaciona.

Que el presente estudio haya abordado las variables protagonista de la noticia y personaje con el que se le relaciona al protagonista de forma abierta, ha permitido confirmar la segunda hipótesis de investigación. De manera previsible, es Juan Carlos I quien obtiene una mayor visibilidad en las noticias analizadas, seguido de su hijo Felipe VI. Como se ha podido observar en el apartado relativo a los resultados, tanto en TVE como en Telecinco, padre e hijo son los actores institucionales que aparecen con un alto porcentaje en los informativos.

Respecto a la valoración de los protagonistas, tanto Televisión Española como Telecinco han ofrecido una imagen claramente negativa de la figura del rey emérito. No obstante, no deja de ser curioso que, tras una evidente concatenación de noticias en detrimento de la figura del ex monarca, TVE haya ofrecido información que aborda los grandes logros de Juan Carlos I en términos democráticos, pues como señalan Cano y Llorca (2017: 33), existe un interés periodístico e histórico en la figura del rey emérito y la transición.

Asimismo, la predisposición de ambas cadenas a ofrecer una valoración más positiva sobre Felipe VI resulta crucial para comprender el tratamiento que se ha ofrecido sobre los protagonistas de la casa real, de cara, la mayoría de las ocasiones, a brindar una imagen de renovación y modernidad institucional, seguido de una evidente separación de la figura de Juan Carlos I respecto a la casa real. Sin embargo, y aunque el marco general que Telecinco ha creado respecto al personaje de Felipe VI es positivo, en algunas de las noticias ofrecidas a la ciudadanía, generan una valoración negativa del actual monarca. Como claro ejemplo de esta práctica informativa, Telecinco enfocaba la crítica al silencio de la institución sobre la salida del rey emérito en la figura del rey Felipe por rehusar a contestar a los periodistas.

Además, la investigación permite trazar un único eje entre las últimas dos hipótesis, pues para conocer la valoración que se ofrecía sobre los protagonistas y comprobar el estilo de presentación de las noticias, ha sido fundamental aplicar la metodología expuesta por Humanes et al. (2013: 570). De esta forma, es interesante destacar que la Televisión pública ha ofrecido más noticias con carácter descriptivo y valoración neutra. Por el contrario, y 
como se ha expuesto anteriormente en los resultados, en la televisión privada el estilo interpretativo y el crítico prevalecen por encima del descriptivo, trasladando parcialmente tanto valoraciones negativas como positivas.

En cualquier caso, el análisis de las valoraciones y el estilo de la noticia evidencia la tercera hipótesis, que queda totalmente corroborada, pues TVE ha mostrado una imagen más neutra de la institución monárquica con un estilo más descriptivo, mientras que Telecinco, acorde a su línea editorial ha mostrado una imagen más negativa sobre la casa real y un estilo crítico que ha llegado a superar las noticias descriptivas.

\section{Conclusiones}

El objetivo principal de esta investigación era comprobar si con la salida del rey emérito de España el pasado mes de agosto de 2020, debido a la acumulación de los casos de corrupción y escándalos privados del propio monarca, los medios de comunicación tradicionales (en este caso la televisión) habían puesto fin realmente al cordón sanitario que la casa real llevaba soslayando durante los años que la institución lleva vigente en España. Pese a la limitación del corpus y el corto periodo analizado, los resultados demuestran que el tratamiento que las cadenas han ofrecido a la opinión pública sobre la institución monárquica tiende a perpetuar ese blindaje y hermetismo informativo.

Tras la salida del monarca, ambas cadenas han tratado de ofrecer una imagen de separación entre la figura de Juan Carlos I y la propia monarquía. Así, han sido numerosas las noticias dedicadas a la diatriba del rey emérito, como los temas relacionados con el blanqueo de capitales o los regalos que el rey emérito hizo a "su amiga íntima" Corina. Estos asuntos han estado a la orden del día en las agendas de los informativos, y su principal protagonista ha sido, evidentemente, el propio Juan Carlos, con una connotación claramente negativa. Además, como se ha expuesto previamente, tanto TVE como Telecinco (aunque en mayor medida TVE), han mostrado a la ciudadanía los comunicados que el Gobierno ofrecía sobre el paradero del rey emérito, en los que se repetía la idea de separación entre "la institución y la persona".

Por el contrario, las televisiones han establecido unos marcos panegíricos entorno a la figura del monarca actual, recalcando la separación con su padre y la idea de transparencia en torno a la institución. Se observa también, y volviendo a cuestiones ya comentadas, una tendencia hacia una crítica más negativa del rey Felipe en Telecinco, adoptando en ocasiones un rechazo total hacia la institución en general. Destaca así un tono más neutro en las noticias de TVE hacia la monarquía y el rey emérito, que, en las noticias referidas a Telecinco, las cuales cuentan con un claro estilo crítico.

Más allá de las diferencias, y a falta de estudios en profundidad sobre el tratamiento que las televisiones ofrecen sobre la casa real, la presente investigación pone de manifiesto que las televisiones, con independencia de la línea editorial, son más críticas con las razones coyunturales de Juan Carlos I, y no con las cuestiones estructurales que evidencian a la monarquía como institución. 
Así pues, para avanzar en el conocimiento de la imagen que las empresas de comunicación ofrecen a la ciudadanía sobre la institución, serán precisas nuevas investigaciones que tengan en cuenta la popularidad de ésta, el discurso que los políticos ofrecen a la ciudadanía, así como lo que piensan las nuevas generaciones al respecto de la casa real. Pero, sobre todo, serán significativos nuevos estudios basados en aportaciones metodológicas y observaciones completas que permitan comprobar, en un futuro, si evidentemente para todos los medios existentes en la actualidad, la monarquía es tratada como una institución regenerada, o si por el contrario, se detecta una nueva tregua informativa en torno a la figura de Felipe VI y a la monarquía en general.

\section{Bibliografía}

Aruguete, N. (2009). Estableciendo la agenda. Los orígenes y la evolución de la teoría de la Agenda Setting [versión electrónica], Ecos de la comunicación, 2(2), 11-38. Recuperado de: http://bibliotecadigital.uca.edu.ar/repositorio/revistas/estableciendo-la-agenda.pdf

Aguilar, M., López, P., \& Echevarría, L. (2013). Cuerpos enclaustrados: el caso de las Ciudades Rurales Sustentables en Chiapas, México. Revista Latinoamericana de Estudios sobre Cuerpos, Emociones y Sociedad, 5(13), 65-73. Recuperado de https://www.redalyc.org/ articulo.oa?id $=273229907006$

Berrocal, G. S. (2005). La información política en televisión: ¿apatía o interés entre los telespectadores?. Comunicar, (25), 1-10. Recuperado de https://dialnet.unirioja.es/descarga/ articulo/2924987.pdf

Cano-O, L., \& Llorca-A, G. (2017). Análisis del discurso oficial de la Casa Real en Twitter durante el periodo de abdicación del Rey Juan Carlos I y la coronación de Felipe VI. Perspectivas de la Comunicación-ISSN 0718-4867, 10(1), 29-54. Recuperado de https://dialnet. unirioja.es/descarga/articulo/7247215.pdf

Carratalá, S. A. (2015). El tratamiento de la Monarquía española en las viñetas de los medios digitales. Dígitos: Revista de Comunicación Digital, 1: 127-154. Recuperado de https:// revistadigitos.com/index.php/digitos/article/view/7/7

Casero-R, A., \& Rabadán, P. L. (2013). La Gestión de fuentes informativas como criterio de calidad profesional. La calidad periodística: teorías, investigaciones y sugerencias profesionales (pp. 73-89). Servei de Publicacions. Recuperado de https://www.researchgate. net/publication/322888769_La_gestion_de_fuentes_informativas_como_criterio_de_calidad_periodistica_Casero_y_Lopez_2013

Donsbach, W.(2014). Cómo entender al periodismo. Selección de la obra de Wolfgang Donsbach.Fernando J. Ruir (comp.). Buenos Aires: Konrad Adenauer Stiftung.

Eugenia, R. M. (2016). Panama Papers y el periodismo en red. Sociales investiga, escritos académicos de extensión y docencia, (2), 108-119. Recuperado en https:// socialesinvestiga. 
MHJournal Vol. 13 (1) | Año 2022 - Artículo nº 7 (200) - Páginas 145 a 167 - mhjournal.org

unvm.edu.ar/ojs/index.php/socialesinvestiga/article/view/89

Fishman, M. (1983). La fabricación de la noticia. Tres Tiempos, Buenos Aires.

Gómez, R. L., Vidales, N. L., \& Torrico, D. V. (2017). La televisión informativa en el entorno digital: análisis de las ediciones diarias de las cadenas generalistas líderes de audiencia en España. Estudios sobre el mensaje periodístico, 24(1), 193-212. Recuperado de https://revistas. ucm.es/index.php/ESMP/article/view/59945

Hoyos, M, M, R. (1999). Las Organizaciones no Gubernamentales (ONGs) y los medios de comunicación. Comunicar, (13), 127-134.

Humanes, M. L. (2001). El encuadre mediático de la realidad social: Un análisis de los contenidos informativos en televisión. ZER - Revista de Estudios de Comunicación, 6(11), 1-11. Recuperado de https://ojs.ehu.eus/index.php/Zer/article/view/6072/5754

Humanes, M. L., Sánchez, M. D. M., de Dios, R. M., \& López-Berini, A. (2013). Pluralismo y paralelismo político en la información televisiva en España. Revista Latina de Comunicación Social, (68), 24-16. Recuperado de https://dialnet.unirioja.es/descarga/articulo/4402842. pdf

Ibáñez, D. B., \& Ecuador, E. S. T. D. C. (2013). Siglo XXI y monarquía. Propuestas para dinamizar la caracterización informativa del rey Juan Carlos I. Área Abierta, 34(3), 1-22. Recuperado de https://dialnet.unirioja.es/servlet/articulo?codigo $=4498609$ \&orden $=425451$ \&info $=$ link

i Céspedes, G. C., \& i Artés, R. F. (2020). Economia mundial: deconstruyendo el capitalismo global (Vol. 12). Edicions Universitat Barcelona.

Igartua, J. J., \& Humanes, M. L. (2004). El método científico aplicado a la investigación en comunicación social. Journal of health communication, 8(6), 513-528. Recuperado de http:// incom.uab.cat/portalcom/wp-content/uploads/2020/01/6_esp.pdf

Igartua, J. J., Muñiz, C., \& Cheng, L. (2005). La inmigración en la prensa española. Aportaciones empíricas y metodológicas desde la teoría del encuadre noticioso. Migraciones. Publicación del Instituto Universitario de Estudios sobre Migraciones, (17), 143-181. Recuperado de https://revistas.comillas.edu/index.php/revistamigraciones/article/view/4220/4043

López-Rabadán, P., \& Vicente-Mariño, M. (2011). Métodos y técnicas de investigación dominantes en las revistas científicas españolas sobre comunicación (2000-2009). Investigar la comunicación en España, 665-679. Recuperado de https://bit.ly/3rwPoe0

Lluch, S. A. (2014). Tratamiento informativo de la Monarquía Española en la prensa digital. De las grandes cabeceras a los medios nativos digitales (Trabajo final de grado). Universitat Jaume I, Castellón. Recuperado de http://repositori.uji.es/xmlui/handle/10234/99647 
López, G. G., \& Valera, O. L. (2013). La información sobre la Monarquía española en los nuevos medios digitales: Eldiario.es y Vozpopuli.com. adComunica. Revista Cientifica de Estrategias, Tendencias e Innovación en Comunicación, 6. 65-81. Recuperado de https://bit.ly/2M5Yn5v

Marín Ll, C. (2017b): El informativo en Televisión. Producción, guion edición audiovisuales. Barcelona, Gedisa.

McCombs, M. E., \& Shaw, D. L. (1993). The evolution of agenda-setting research: Twenty-five years in the marketplace of ideas. Journal of communication, 43(2), 58-67. Recuperado de https://academic.oup.com/joc/article-abstract/43/2/58/4160155

Pablos, J. M. D., \& Abreu, A. A. (2009). Prensa española y monarquía: el” silencio crítico" se termina. Estudio de caso. Anàlisi: quaderns de comunicació i cultura, (39), 0237-253. Recuperado de https://ddd.uab.cat/record/54970

Paulón, M. (2018). “Ahora más que nunca”: una experiencia mediática contrabegemónica (Bachelor's thesis, Facultad de Ciencia Política y Relaciones Internacionales).

Ramos, F. F (2012). Los escándalos de la Corona española en la prensa digital y el futuro de la monarquía. De la amnesia y el silencio cómplice al tratamiento exhaustivo los medios. Razón y palabra, 17(79), 1-27. Recuperado de https://dialnet.unirioja.es/servlet/ articulo?codigo $=4737821$

-- (2013). El "tabú" periodístico de la monarquía en España. La crisis real y la crisis coyuntural. Revista latina de comunicación social, (68), 217-248. Recuperado de https://dialnet. unirioja.es/servlet/articulo? codigo $=4168523$

Ramos-Ruiz, A. (2015). El tratamiento de la violencia de género en los informativos televisivos (Tesis doctoral). UMA, Málaga Editorial. Recuperado de https://riuma.uma.es/xmlui/handle/10630/13593

Salaverría, R., Buslón, N., López-Pan, F., León, B., López-Goñi, I., \& Erviti, M. C. (2020). Desinformación en tiempos de pandemia: tipología de los bulos sobre la Covid-19. Elprofesional de la información (EPI), 29(3), 1-15. Recuperado de http://profesionaldelainformacion. $\mathrm{com} /$ contenidos/2020/may/salaverria-buslon-lopez-leon-lopez-erviti.pdf

Silveira, A. C. M., Hartmann, C., \& Schwartz, C. (2020). Polarização e blindagem midiática: o questionamento da mediação jornalística. Index. comunicación: Revista científica en el ámbito de la Comunicación Aplicada, 10(2), 83-114.

Uriarte, B, E. (2001). La crisis de la imagen de la política y de los políticos y la responsabilidad de los medios de comunicación. Revista de estudios políticos, (111), 45-64.

Valera, L. (2019). “Circulación y recepción del mensaje político” [Material de aula]. Universidad de Valencia. Valencia, España. 
MHJournal Vol. 13 (1) | Año 2022 - Artículo no 7 (200) - Páginas 145 a 167 - mhjournal.org

Velasco, M. A. M. (2018). Monarquía y medios de comunicación: de la Transición a Corinna zu Sayn-Wittgenstein. Observatorio (OBS*), 12(3), 122-137. Recuperado de http://obs.obercom.pt/index.php/obs/article/view/1203

Vicente, M., \& Monclús, B. (2010): "La creación de imagen de marca a través de los servicios informativos: claroscuros en los noticieros españoles”. En Actas del II Congreso Internacional de Teoría y Técnica de los Medios Audiovisuales. Castellón, Universitat Jaume I, mayo de 2009. Madrid, Ediciones de Ciencias Sociales, pp. 207- 215. 


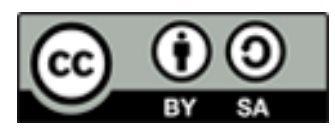

Licencia Creative Commons

Miguel Hernández Communication Journal

mhjournal.org

\section{Cómo citar este texto:}

David Lava Santos y Isaac Pardo de Pedro (2022): La imagen de la Casa Real en los medios de comunicación españoles: estudio sobre la cobertura informativa en TVE y Telecinco tras la salida de Juan Carlos I al extranjero (3 de agosto de 2020), en Miguel Hernández Communication Journal, Vol. 13 (1), pp. 145 a 167 Universidad Miguel Hernández, UMH (Elche-Alicante). DOI: 10.21134/mhjournal.v13i.1443 